\title{
The use of Medpor coated tear drainage tube in conjunctivodacryo- cystorhinostomy
}

\begin{abstract}
Purpose To analyse outcomes of lacrimal bypass surgery with the Medpor coated tear drainage tube.

Methods A total of 26 eyes in 26 patients with persistent epiphora who failed

canaliculoanastomosis and dacryocystorhinostomy were treated by the lacrimal bypass surgery with the Medpor coated tear drainage tubes. Ten cases of severe obstruction of punctum and canaliculi and $\mathbf{1 6}$ cases with both upper system and lacrimal sac obstruction comprised this cohort of patients. Results No tube extrusion or displacement was observed after 6-28 months of follow-up. Complete or significant resolution of epiphora was achieved in $23 / 26$ cases $(88.5 \%)$. Luminal obstruction by debris was noted in nine eyes, ocular discomfort in four, improper tube size selection in two, malposition in one, infection in one, diplopia in one, corneal abrasion in one, and reflux of intranasal secretion into fornix in another.

Conclusion Medpor coated tear drainage tube offers tube stabilization in minimizing tube extrusion and displacement.
\end{abstract}

Eye (2008) 22, 1148-1153; doi:10.1038/sj.eye.6702870; published online 25 May 2007

Keywords: lacrimal duct occlusion; lacrimal bypass surgery; Medpor coated tear drain

\section{Introduction}

Conjunctivodacryocystorhinostomy (CDCR) with insertion of Jones tube, ${ }^{1}$ which is a hollow glass tube to serve as a direct conduit of tear drainage from the medial canthal recess into the nasal cavity, is a well accepted treatment for severe lacrimal canalicular obstruction.
X Fan, X Bi, Y Fu and $\mathrm{H}$ Zhou

Complications associated with standard Jones tube placement are well recognized, including tube extrusion, malposition, obstruction, diplopia so on. Many patients may require reoperations to optimized tube placement. ${ }^{2,3}$ Many investigators have tried to improve the surgical technique and bypass tube design to reduce complications. Chung et al ${ }^{4}$ used the rubber-tipped Jones tube to prevent the medial end of the tube from abrading the nasal septal lining. Trotter and Meyer ${ }^{5}$ used the intranasal endoscopic CDCR to optimize Jones tube placement. Can et $a l^{6}$ performed CDCR with insertion of Jones tube surrounded with a buccal mucosal graft with some success. An ideal lacrimal bypass tube should be easy to insert, remains in situ without migration, comfortable for patients, and can be removed for cleaning if needed.

The purpose of our study is to evaluate the effectiveness of lacrimal bypass surgery with the Medpor coated tear drainage tube in achieving tear clearance, stability.

\section{Materials and methods}

\section{Study population}

Twenty-six patients (26 eyes) were performed lacrimal bypass surgery with Medpor coated tear drainage tube between November 2002 and December 2004 at Department of Ophthalmology, Shanghai Ninth People's Hospital, Shanghai Jiaotong University School of Medicine. All patients had severe epiphora. Of these cases, 17 were male subjects and nine were female subjects. Their ages ranged from 16 to 56 years old (mean 36). The mean duration of symptom was 20.2 months (range: 1 month to 9 years). The aetiology of lacrimal outflow obstruction in all cases was due to secondary to injury. 
Preoperative work-up included obtaining pertinent medical and ocular history, visual acuity, medial canthal configuration, eyelid position, and CT image. All patients underwent preoperative lacrimal probing/ irrigation to confirm the location of the outflow obstruction. Twelve cases (46\%) had inferior canalicular obstruction, six cases (23\%) had obstruction of inferior canaliculi and superior canaliculi, six cases $(23 \%)$ of common canalicular involvement, and two patients $(8 \%)$ of punctual occlusion. Other deformities included the defect of lacrimal sac in 16 patients according to primary surgery record, nasolacrimal duct fractures and nasoorbitoethmoid fractures in seven cases, medial canthal deformities in 12 patients, eyelid deformities or upper lid ptosis in seven patients.

All patients were seen at 1 week and 1, 3, and 6 months after surgery. Patients with a minimum of 6 months follow-up were included in the study, follow-up ranged from 6 to 28 months. Patient characteristics and surgical outcomes are shown in Table 1.

\section{Materials}

Medpor (Porex Surgical Inc., Newnan, GA, USA) coated tear drainage tube (Figure 1) were inserted in the

Table 1 Patient characteristics and study variables for CDCR and conjunctivorhinostomy with Medpor coated tear drain insertion

\begin{tabular}{|c|c|c|c|c|c|c|c|c|c|}
\hline Case/side & Age/sex & Obstruction site ${ }^{\mathrm{a}}$ & $\begin{array}{l}\text { Course } \\
\text { (MOS) }\end{array}$ & $\begin{array}{l}\text { Surgical } \\
\text { technique }^{\mathrm{b}}\end{array}$ & $\begin{array}{l}\text { Tube length } \\
\text { (mm) }\end{array}$ & $\begin{array}{l}\text { Follow-up } \\
\text { (MOS) }\end{array}$ & Result $^{\mathrm{c}}$ & Complication $^{\mathrm{d}}$ & $\begin{array}{l}\text { Secondary } \\
\text { procedure }\end{array}$ \\
\hline $1 \mathrm{~L}$ & $16 \mathrm{~F}$ & $\begin{array}{l}\text { LC, DLS } \\
\text { ULC, }\end{array}$ & 24 & $\begin{array}{l}\text { b, MCLF } \\
\text { b, MCLF, }\end{array}$ & 24 & 8 & Complete S & Obstruction & Excision \\
\hline $2 \mathrm{~L}$ & $42 \mathrm{M}$ & DLS & 18 & COP & 26 & 11 & Significant S & Obstruction & Excision \\
\hline $3 \mathrm{R}$ & $40 \mathrm{M}$ & $\mathrm{LC}$ & 12 & a & 24 & 12 & Complete S & Discomfort & - \\
\hline $4 \mathrm{~L}$ & $38 \mathrm{M}$ & $\mathrm{CC}$ & 24 & $\mathrm{a}, \mathrm{MCLF}$ & 26 & 18 & Complete S & - & - \\
\hline $5 \mathrm{R}$ & $38 \mathrm{M}$ & PO, DLS & 60 & b, EDR & 24 & 18 & Failure & Obstruction & Excision \\
\hline $6 \mathrm{R}$ & $56 \mathrm{M}$ & $\mathrm{LC}$ & 8 & a, EDR & 26 & 18 & Complete S & - & - \\
\hline $7 \mathrm{R}$ & $53 \mathrm{~F}$ & CC, DLS & 36 & b, MCLF & 26 & 24 & Complete S & $\begin{array}{l}\text { Obstruction } \\
\text { Diplopia, }\end{array}$ & Excision \\
\hline $8 \mathrm{R}$ & $40 \mathrm{M}$ & $\begin{array}{l}\text { ULC } \\
\text { ULC, }\end{array}$ & 6 & a & 24 & 8 & Complete S & Disomfort & - \\
\hline $9 \mathrm{~L}$ & $36 \mathrm{M}$ & DLS & 12 & b, EDR & 24 & 6 & Complete S & - & - \\
\hline $10 \mathrm{R}$ & $25 \mathrm{~F}$ & $\begin{array}{l}\text { LC, DLS } \\
\text { ULC, }\end{array}$ & 18 & $\mathrm{~b}$ & 20 & 25 & Complete S & Obstruction & Excision \\
\hline $11 \mathrm{~L}$ & $38 \mathrm{M}$ & DLS & 17 & b, MCLF & 24 & 6 & Significant S & $\begin{array}{l}\text { Malposition } \\
\text { Improper }\end{array}$ & $\overline{\text { Exchange }}$ \\
\hline $12 \mathrm{R}$ & $34 \mathrm{M}$ & LC, DLS & 24 & $\mathrm{~b}$ & 20 & 28 & Complete S & Tube & Tube \\
\hline $13 \mathrm{R}$ & $39 \mathrm{M}$ & LC ,DLS & 10 & b, EDR & 24 & 28 & Complete S & Improper tube & Grind tube \\
\hline $14 \mathrm{~L}$ & $23 \mathrm{M}$ & $\begin{array}{l}\text { LC } \\
\text { ULC, }\end{array}$ & 24 & $\mathrm{a}, \mathrm{MCLF}$ & 26 & 27 & Significant S & $\begin{array}{l}\text { Obstruction } \\
\text { Corneal }\end{array}$ & Excision \\
\hline $15 \mathrm{R}$ & $33 \mathrm{~F}$ & DLS & 108 & $b, \mathrm{MCLF}$ & 24 & 24 & Complete S & Abrasion, & - \\
\hline $16 \mathrm{R}$ & $35 \mathrm{M}$ & $\mathrm{LC}$ & 9 & $\mathrm{a}, \mathrm{MCLF}$ & 24 & 22 & Complete S & Obstruction & Excision \\
\hline $17 \mathrm{~L}$ & $36 \mathrm{~F}$ & $\mathrm{CC}$ & 7 & $\mathrm{a}, \mathrm{MCLF}$ & 24 & 18 & Complete S & Discomfort & - \\
\hline $18 \mathrm{~L}$ & $41 \mathrm{M}$ & LC, DLS & 9 & b, EDR & 22 & 6 & Failure & Infection & $\begin{array}{l}\text { Remove } \\
\text { tube }\end{array}$ \\
\hline $19 \mathrm{~L}$ & $48 \mathrm{~F}$ & LC & 36 & $\mathrm{a}, \mathrm{MCLF}$ & 24 & 8 & Complete S & - & - \\
\hline $20 \mathrm{R}$ & $22 \mathrm{M}$ & $\mathrm{CC}$ & 1 & $\mathrm{a}$ & 22 & 12 & Complete S & Obstruction & Excision \\
\hline $21 \mathrm{R}$ & $25 \mathrm{~F}$ & LC, DLS & 12 & $\mathrm{~b}, \mathrm{MCLF}$ & 20 & 9 & Complete S & - & -- \\
\hline $22 \mathrm{~L}$ & $27 \mathrm{M}$ & CC, DLS & 10 & $\mathrm{~b}$ & 24 & 18 & Failure & ROIF & $\begin{array}{l}\text { Remove } \\
\text { tube }\end{array}$ \\
\hline $23 \mathrm{~L}$ & $35 \mathrm{~F}$ & CC, DLS & 3 & $\mathrm{~b}$ & 22 & 24 & Complete S & Discomfort & - \\
\hline $24 \mathrm{R}$ & $43 \mathrm{M}$ & $\begin{array}{l}\text { LC } \\
\text { ULC, }\end{array}$ & 18 & A, MCLF & 26 & 6 & Complete S & - & - \\
\hline $25 \mathrm{~L}$ & $45 \mathrm{~F}$ & $\begin{array}{l}\text { DLS } \\
\text { PO, }\end{array}$ & 9 & $b, \mathrm{COP}$ & 24 & 12 & Complete S & Obstruction & Excision \\
\hline $26 \mathrm{R}$ & $36 \mathrm{M}$ & DLS & 10 & $\mathrm{~b}$ & 26 & 9 & Complete S & - & - \\
\hline
\end{tabular}

${ }^{a}$ LC, lower canaliculi; ULC, upper and lower canaliculi; CC, common canaliculi; PO, punctual occlusions; DLS, defect of lacrimal sac.

$\mathrm{b}$ a, CDCR with Medpor coated tear drain; b, Conjunctivorhinostomy with Medpor coated tear drain insertion; MCLF, medial canthal ligament fixation; COP, correction of ptosis; EDR, eyelid defect repair.

'S, success.

${ }^{\mathrm{d}}$ ROIF, reflux of intranasal secretion. 


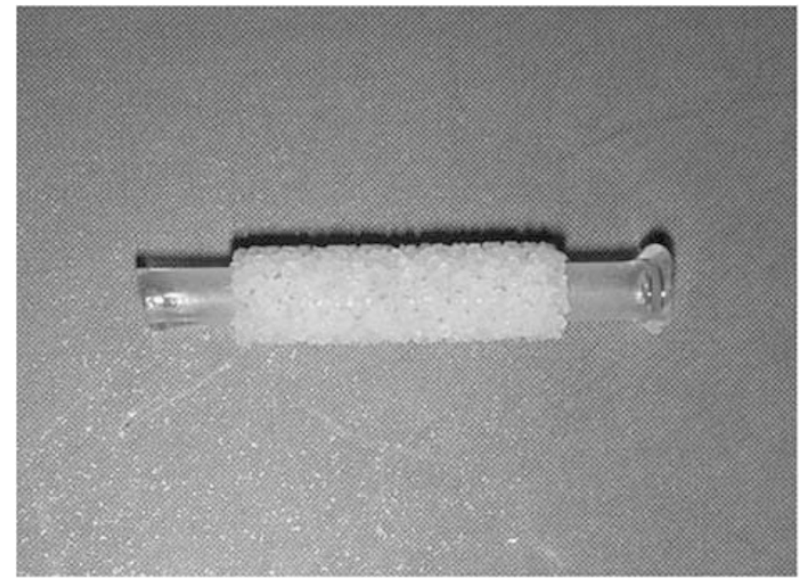

Figure 1 Medpor coated tear drainage tube.

standard CDCR technique. The tube is manufactured from borosilicate glass coated with a linear, high-density polyethylene porous biomaterial coating. High-density porous polyethylene (HDPP) has been shown to have good tissue tolerance and stability. The porosity of the HDPP biomaterial coating is maintained large, with average pore sizes larger than $100 \mu \mathrm{m}$ and pore volume in the 50\% range, allowing for tissue ingrowth. The glass inner core conducts tears and other fluids from the medial canthal recess into the nasal cavity. The drainage tubes are available in $3.5 \mathrm{~mm}$ diameter with variable lengths for customized fitting.

\section{Surgical technique}

The procedure was performed under general anaesthesia in 16 patients and under local anaesthesia with intravenous sedation in 10 patients. Ten procedures were performed by external dacryocystorhinostomy (DCR) approach with Medpor coated tear drain implantation ${ }^{1-3}$ and 16 patients who had no lacrimal sac were carried out by conjunctivorhinostomy with Medpor coated tear drain insertion. The length of tubes used ranged from 20 to $26 \mathrm{~mm}$.

CDCR with Medpor coated tear drain: Incisions including standard DCR incision, $\mathrm{Y}$ incision, and local scar incision were made in the medial canthus. After careful anatomic blunt dissection of the tissue planes, the medial canthal ligament and the lacrimal sac were found. The periosteum was elevated and a Medicon punch was used to create a bony osteotomy of at least 12 by $12 \mathrm{~mm}$ in the medial wall of the lacrimal fossa. Flaps were created in the lacrimal sac and lateral nasal mucosa, and then the posterior flaps anastomosed where possible. The inferior third of the caruncle was excised and a tract between this site and the nose made using straight iris scissors. The tract was dilated and a fine
Kirshner wire used to estimate the desired length of the tube such that, it would lie in the nasal cavity without touching the nasal septum. It is difficult to insert the Medpor coated tear drain into the tract, so the thin plastics membrane was used to wrap the tube.

The Medpor tube was introduced into the track, and then the thin plastics membrane carefully pulled out.

Examination under endoscopy was performed to check the positioning of the distal end of the tube. After satisfactory position was obtained, function of the new conduit was checked by irrigation of fluorescein solution from the medial canthal region. The proximal end of the tube was sutured using 5-0 Vicryl at the medial canthus. The anterior lacrimal and nasal flaps were anastomosed and the overlying tissue closed. In some cases with medial canthus deformities, the medial canthal ligament was fixed to the posterior edge of the bone hole before the skin incision was closed.

Conjunctivorhinostomy with Medpor coated tear drain insertion: The incision and osteotomy were same as the procedure of CDCR with Medpor coated tear drain. Flaps were created in lateral nasal mucosa. The caruncle was partly excised. A tract between caruncle and the nose was made and dilated, and then the Medpor tube of appropriate length was introduced into the track.

The Medpor tube should ultimately lie more vertical in orientation than horizontal. The nasal flap was sutured to the Medpor of the distal end of the tube, and periosteal, muscle layers, and conjunctiva were closed with 5-0 Vicryl.

The intranasal position of the tube was assessed by endoscopy (Figure 2). Postoperative antibiotic drops were prescribed for 1 week.

As the aetiology of outflow obstruction in all patients was secondary to trauma, other eyelid deformities were corrected at same time. Twelve patients had medial canthal ligament fixation, and seven patients underwent eyelid defect repair or correction of ptosis at the same time.

\section{Results}

\section{Successful rate}

The same surgical group successfully completed all procedures, and there were no intraoperative complications. Success was defined by the patency of the Medpor tube on testing with irrigation accompanied by the subjective relief of epiphora by the patient's description. A completely successful outcome was defined as a comfortable, epiphora-free eye, with the patency of lacrimal passage verified by lacrimal irrigation and a normal dye clearance test. Twenty-one patients $(80.8 \%)$ were assessed to have achieved 
completely successful outcome. A significantly successful outcome, defined as symptomatic improvement but without complete relief of epiphora, was achieved in two patients. A complete or significant improvement of relief of epiphora was achieved in $88.5 \%$ cases (23 of 26). The patients who were treated by CDCR with Medpor tube insertion had higher successful rate than those of conjunctivorhinostomy with Medpor tube (Table 1). It was found that all patients (10 cases) with CDCR had a comfortable eye with complete or significant improvement of relief of epiphora during follow-up, whereas three of 16 patients with conjunctiovorhinostomy did not get a patency tube postoperation and the successful rate was $83 \%$.

Unsuccessful outcome defined as persistent epiphora in the presence of well-positioned Medpor tube was seen in three cases. One patient no longer complains of tearing, but always had reflux of intranasal secretion into the fornix. The patient requested tube removal. One patient developed an abscess and purulent discharge in the medial canthal region and requested tube removal despite total resolution of tearing symptom for 6 months. The third patient had medial obstruction of the tube caused by nasal mucosal overgrowth. The hypertrophic mucosa was excised under the endoscope, but mucosal blockage of the tube recurred 2 months later.

\section{Complications}

The complication of mucosal tissue hypertrophy leading to tube obstruction is most likely due to foreign body

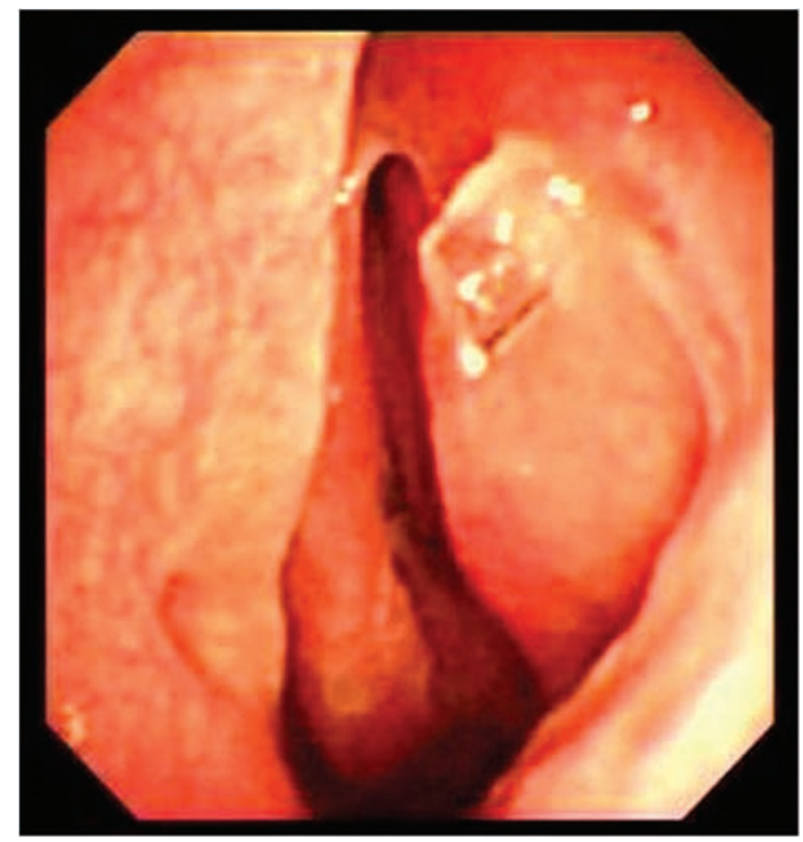

Figure 2 Intranasal position of the distal end of the tube. reaction. No patients exhibited the complications of tube extrusion or severe displacement (Table 2).

(1) Obstruction: In nine cases, tube obstruction occurred approximately 3 months after surgery. Six cases of proximal tube obstruction were due to conjunctival overgrowth of granulation tissue. The granulation tissue was excised and the stump cauterized to prevent the tissue regrowth. Distal tube blockage was caused by nasal mucosal overgrowth in three cases. The hypertrophic tissues were excised endoscopically. Distal blockage recurred in one case, and the patient refused further surgery.

(2) Improper length of tube: One patient complained of nasal pain on second postoperative day. Endoscopic inspection revealed the Medpor tube was in direct contact with the nasal septum. The distal end of the tube was shortened by $2-3 \mathrm{~mm}$ by grinding the tip with an electric drill. Reducing the length of the tube resolved the nasal discomfort. Another patient required a second procedure to exchange to a longer tube for optimal positioning.

(3) Malposition: One case was found to have a horizontal orientation of the tube, requiring a new insertion tract for a more vertical orientation.

(4) Discomfort: Foreign body sensations due to contact of the proximal end of the tube against the conjunctiva were experienced by several patients. This symptom was transient in nature, however.

(5) Others: Including infection, diplopia, corneal abrasion, and nasal secretion countercurrent. The patient with diplopia or corneal abrasion recovered normal himself within 3 days after operation.

\section{Discussion}

Lacrimal drainage system obstruction is a common condition encountered in clinical practice. Canalicular obstruction and traumatic canalicular defect are best managed by CDCR with insertion of a bypass tube. The

Table 2 Complications of lacrimal bypass surgery performed on 26 eyes

\begin{tabular}{llrr}
\hline Complications & & No. & Rate (\%) \\
\hline Tube obstruction & Conjunctival overgrowth & 6 & 23.1 \\
& Nasal mucosal granulation & 3 & 11.5 \\
& Malposition & 1 & 3.8 \\
Tube problems & Improper tube length & 2 & 7.7 \\
& Discomfort & 4 & 15.4 \\
Diplopia & & 1 & 3.8 \\
Infection & & 1 & 3.8 \\
Corneal abrasion & 1 & 3.8 \\
Nasal secretion & & 1 & 3.8 \\
$\quad$ countercurrent & & & \\
\hline
\end{tabular}


ideal bypass tube should be straight rather than curved, hydrophobic, some rigidity, less tissue reaction, and good biocompatibility. It can be made up of various materials, such as polypropylene, ${ }^{7}$ silicone, ${ }^{8}$ Teflon, ${ }^{9}$ and Pyrex glass. Among these, Pyrex glass tube is closest to fulfilling the ideal characteristics of a tear drainage tube. Although the pyrex tube is successful in the majority of patients in relieving tearing, the main shortcoming of a Jones tube is extrusion, with extrusion rates reported as high as $18-51 \% .^{2,10,11}$ Using the Medpor tube as bypass tube, an improvement or complete relief of epiphora was achieved in 23 cases (88.5\%), and the tube extrusion or displacement was not seen in this study. It demonstrates that the inner glass core-coated HDPP to the outer surface retains all the benefits of the glass tube and the added advantage of tube stability and retention. The inner glass core conducts fluid into the nasal cavity, whereas the thin covering of linear HDPP permits tissue ingrowth for tube stabilization. The porous polyethylene coating is the same material that has been used successfully in surgical implants for over 15 years. The interconnecting, omni directional pore structures, which allow for rapid fibrovascular tissue integration, good biocompatibility, resist infection, no absorption, and stable quality, have widely been used in orbital and craniofacial reconstruction. ${ }^{12}$

Reasons for the three failures were recurrent proximal blockage of the tube, infection, and reflux of intranasal secretion into the fornix. Compared with previous studies on CDCR with insertion of Jones tube (Table 3) ${ }^{13-15}$ there was no tube extrusion and severe displacement in our study, as the Medpor coat has good biocompatibility, which allow fibrovascular ingrown to obtain positional stability. Only one patient exchanged his tube because of the inserted tube too short, the rate of tube exchanging was much less than the Jones tube insertion.

We found that the most common complication was Medpor tube obstruction. Early obstruction was caused by soft tissue swelling, whereas the long-term obstruction was caused by overgrowth of conjunctiva or nasal mucosa. Obstruction occurred approximately 3 months after surgery, six cases were proximal obstruction of the tube and three patients had nasal blockage of the tube. The hypertrophic tissues were excised, and good results were achieved except one patient who had blockage again and refused further surgical correction. The rate of tube obstruction was higher than previous reports (Table 3). The reason for the obstruction is not clear, may be related to the porous polyethylene coated to the outer surface of tube. The HDPP is irritative to the soft tissue, when placed adjacent to a contaminated environment, such as the nasal cavity, can lead to pyogenic granuloma formation, which leads to secondary tube obstruction.

Less common complications included infection, discomfort, diplopia, corneal abrasion, and reflux of intranasal secretion into the fornix. The one patient with diplopia and the other with corneal abrasion recovered uneventfully within 3 days. We believe both cases were not Medpor tube related complications. The recurrent obstruction of the tube, infection and retrograde reflux of intranasal secretion accounted for the surgical failures in three patients. One patient had recurrent proximal blockage of the tube that was caused by nasal mucosal overgrowth of granulation tissue, and declined surgery for correction. Others were the pyogenic granuloma and nasal secretion countercurrent, which led to remove the Medpor tube. It is also difficult to remove the Medpor tube, because the Medpor coat allows fibrovascular ingrown to obtain stability.

It must be emphasized that bypass tubes should be used only as a last resort when canalicular reconstruction is impossible. All forms of artificial tear drainage replacement may be associated with either short- or long-term complications, however, in selected cases, bypass lacrimal surgery can provide appropriate relief of epiphora. In this study, lacrimal bypass surgery with the Medpor coated tear drain provided a high success rate associated with fewer complications than have been reported with the traditional Jones tear drain.

Table 3 Comparison of current study results with previous studies

\begin{tabular}{|c|c|c|c|c|c|c|}
\hline & \multirow[t]{2}{*}{ No. of cases } & \multicolumn{4}{|c|}{ Most common complications (\%) } & \multirow[t]{2}{*}{ Rate of tube exchange (\%) } \\
\hline & & Extrusion & Obstruction & Displacement & Infection & \\
\hline Current study (2005) & 26 & $*^{*} 0$ & 35 & $*^{*} 0$ & 3.8 & 3.8 \\
\hline Lim et $a l^{13}$ & 49 & 49 & 47 & 33 & 8 & - \\
\hline Lee $e t a l^{14}$ & 124 & 1.6 & 15 & 5.6 & 5.6 & 8 \\
\hline Rosen $e t a l^{3}$ & 121 & 20 & 11 & 6 & - & 17.4 \\
\hline Steinsapir et $a l^{11}$ & 79 & 51 & 23 & 22 & 3 & 17.3 \\
\hline Hurwitz and Rutherford ${ }^{15}$ & 23 & 18 & 13 & - & - & - \\
\hline
\end{tabular}




\section{Acknowledgements}

We are grateful to Dr David T Tse (Bascon Palmer Eye Institute, Department of Ophthalmology, University of Miami School), Dr Yip Chee Chew (The Eye Institute, Tan Tock Seng Hoapital) for their help and their support. This work was supported by grants from the Science and Technology Commission of Shanghai and the Hygiene Commission of Shanghai.

\section{References}

1 Jones LT. Conjunctivodacryocystorhinostomy. Am J Ophthalmol 1965; 59: 773-783.

2 Sekhar GC, Dortzbach RK, Gonnering RS, Lemke BN. Problems associated with conjunctivodacryocystorhinostomy. Am J Ophthalmol 1991; 112: 502-506.

3 Rosen N, Ashkenazi I, Rosner M. Patient dissatisfaction after functionally successful conjunctivodacryocystorhinostomy with Jones tube. $A m$ J Ophthalmol 1994; 117: 636-642.

4 Chung YJ, Kim G, Sohn BK. Conjunctivorhinostomy with rubber-tipped Jones tube. Ann Plast Surg 2004; 52: 68-71.

5 Trotter WL, Meyer DR. Endoscopic conjunctivodacryocystorhinostomy with Jones tube placement. Ophthalmology 2000; 107: 1206-1209.
6 Can I, Can B, Yarangumeli A, Gurbuz O, Tekelioglu M, Kural G. CDCR with buccal mucosal graft: comparative and histopathological study. Ophthalmic Surg Lasers 1999; 30: 98-104.

7 Hurwitz JJ. New polypropylene tube to stent or bypass the lacrimal system. Can J Ophthalmol 1984; 19: 261-265.

8 Reinecke RD, Carroll JM. Silicone lacrimal tube implantation. Trans Am Acad Ophthalmol Otolaryngol 1969; 73: 85-90.

9 Hurwitz JJ. Teflon tubes for stenting and bypassing the lacrimal drainage pathways. Ophthalmic Surg 1989; 20: 855-859.

10 Zilelioglu G, Gunduz K. Conjunctivodacryocystorhinostomy with Jones tube. A 10-year study. Doc Ophthalmol 1996-1997; 92: 97-105.

11 Steinsapir KD, Glatt HJ, Putterman AM. A 16-year study of conjunctival dacryocystorhinostomy. Am J Ophthalmol 1990; 109: 387-393.

12 Rubin PA, Bilyk JR, Shore JW. Orbital reconstruction using porous polyethylene sheets. Ophthalmology 1994; 101: $1697-1708$

13 Lim C, Martin P, Benger R, Kourt G, Ghabrial R. Lacrimal canalicular bypass surgery with the Lester Jones tube. Am J Ophthalmol 2004; 137: 101-108.

14 Lee JS, Jung G, Lee JE, Oum BS, Lee SH, Rho HJ. The treatment of lacrimal apparatus obstruction with the use of an inner canthal Jones tube insertion via a transcaruncular route. Ophthalmic Surg Lasers 2001; 32: 48-54.

15 Hurwitz JJ, Rutherford S. Computerized survey of lacrimal surgery patients. Ophthalmology 1986; 93: 14-19. 